\title{
Acompañando la inserción de profesores nóveles en establecimientos municipales de Valparaíso: \\ La experiencia de los Talleres de Educación Democrática (TED)
}

\author{
Accompanying the novice teachers insertion in the \\ municipal schools in Valparaiso: \\ The experience in Democratic Education Workshops \\ $(D E W)$
}

Ricardo Hevia Rivas ${ }^{1}$

Jahel Ramírez Soto ${ }^{2}$

Resumen

El artículo sistematiza una experiencia de Talleres de Educación Democrática (TED) aplicada al Programa de Inserción de Docentes Nóveles de la Corporación Municipal de Valparaíso.

En los talleres se invitó a profesores que recién iniciaban su trabajo profesional a vivir una experiencia grupal de aprendizaje, desarrollando investigaciones protagónicas sobre su práctica pedagógica. A través de la reflexión promovida en esta experiencia grupal y en la investigación, los profesores nóveles pudieron imaginar formas alternativas de asumir su rol docente, trabajar en grupos más democráticos y favorecer aprendizajes más autónomos.

Palabras clave: Inserción de docentes nóveles, Talleres de Educación Democrática (TED), rol docente, vectores del aprendizaje grupal, concepción de aprendizaje.

1 Programa de Inserción de Docentes Nóveles de la Corporación Municipal de Valparaíso. Profesor de Filosofía, Pontificia Universidad Católica de Chile. Master of Arts in Comparative Education, Stanford University, California, Estados Unidos. E-mail r.heviarivas@gmail.com

2 Programa de Inserción de Docentes Nóveles de la Corporación Municipal de Valparaíso. Profesora de Educación Básica, Licenciada en Educación, Universidad Academia de Humanismo Cristiano, Santiago, Chile. E-mail jahelmagdalena@gmail.com 


\begin{abstract}
The article systematizes the Democratic Education Workshops (DEW) experience applied to the 'Insertion Program for Novice Teachers of the Valparaiso Municipality Corporation'.

In these workshops, novice teachers were invited to participate in a group learning experience developing pedagogical researches on their own professional performance. This experience allows them to imagine alternative ways of assuming their teachers' role, to promote more democratic working groups, and to favor more autonomous learning.
\end{abstract}

Key words: Novice teacher insertion, Democratic Education Workshops $(D E W)$, teacher role, group learning vectors, concept of learning.

\title{
Introducción
}

En su origen, los TED se vinculan a la experiencia de los Talleres de Educadores (TE) promovida por el Centro de Perfeccionamiento, Experimentación e Investigación Pedagógica (CPEIP) a comienzos de los años 70 . De acuerdo a su promotor, Rodrigo Vera, los TE eran pequeños grupos de docentes de asignatura que se reunían a analizar crítica y colectivamente su práctica para mejorarla. Después del golpe de Estado, durante los años ochenta y comienzos de los noventa, las ideas de los TE se retomaron y expandieron, esta vez desde el Programa Interdisciplinario de Investigaciones en Educación (PIIE) bajo el nombre de Talleres de Educación Democrática (TED), convirtiéndose en una experiencia de formación docente vinculada a los Movimientos de Renovación Pedagógica y a las actividades gremiales del Colegio de Profesores de Chile.

Los TED tuvieron tres grandes ejes de trabajo:

- La construcción de una nueva cultura escolar, mediante la generación de condiciones adecuadas para que los actores educativos (profesores y estudiantes) se convirtieran en protagonistas de sus aprendizajes; 
- La inserción sistemática del trabajo pedagógico en las organizaciones gremiales para convertir a los educadores en los protagonistas del mejoramiento de la calidad docente;

- La comprensión de la docencia en el sistema escolar como una labor profesional y no solo de carácter técnico.

Desde el punto de vista teórico, los TED se apoyan en una conceptualización sobre aprendizaje y sobre el trabajo en grupos operativos proveniente de la Escuela de Psicología Social de Enrique Pichón Riviere, de Buenos Aires.

La experiencia que se sistematiza en este artículo forma parte del Proyecto "Hacia un modelo de intervención para la inserción profesional de profesores nóveles en la educación municipalizada chilena: Una experiencia piloto en la Corporación Municipal de Valparaíso-2010”, coordinado por la profesora Lina Peralta (Peralta, Martínez \& González, 2011). Este proyecto consistió en la aplicación de cinco dispositivos para acompañar a los docentes en su inserción al sistema de educación formal: seminarios, jornadas, pasantías, mentorías y los Talleres de Educación Democrática. El presente artículo da cuenta solo del componente de los TED.

Los talleres se desarrollaron entre agosto y noviembre de 2010. Participaron veinte profesores nóveles, divididos en dos grupos de diez docentes cada uno, distribuidos según su jornada laboral. Los docentes tenían entre uno y tres ańos de experiencia profesional y todos trabajaban en escuelas municipales de Valparaíso. El 75\% de los participantes era de género femenino. Cada grupo tuvo ocho sesiones de trabajo, de 90 minutos cada una.

Dos personas conformaban el equipo de coordinación: un coordinador principal, a cargo de sistematizar y devolver al grupo lo ocurrido en la sesión anterior, y de coordinar el momento de trabajo grupal; y un coordinador asistente, a cargo de registrar las sesiones. Ambos analizaban los registros para preparar la devolución que era presentada al grupo en el momento informativo de la siguiente sesión.

El propósito de este artículo es sistematizar la experiencia vivida por los docentes nóveles, desde la perspectiva del logro de los objetivos de capacitación de la experiencia, a saber: 
- Reconocimiento de las principales dificultades que enfrentan para modificar el rol docente;

- Desarrollo de la capacidad para trabajar en grupos cooperativos y autogestionados;

- Aplicación de la capacidad de distinguir signos y contrasignos de aprendizajes.

Para lograr estos objetivos los talleres se organizaron sobre la base de tres componentes:

- La tarea principal: la investigación docente.

- La opción de trabajo: el grupo cooperativo.

- La modalidad de evaluación: el aprendizaje autónomo.

El método de investigación privilegiado en el Taller fue la investigación protagónica (IP) que define a la propia práctica docente como su objeto de estudio. La IP se desenvuelve como una reflexión crítica sobre el trabajo cotidiano de los profesores, con el propósito de transformar sus marcos de referencia con y desde los cuales actúan (Vera, 1988a, 1988b, 1988c; Inostroza, 1996).

En la IP se analizan "episodios críticos" vividos por los participantes, reconstruyéndolos y preguntándose por las concepciones pedagógicas comprometidas en ellos. El supuesto es que esas concepciones que las han ido internalizando a lo largo de su trayectoria escolar y profesional, son las que fundamentan muchas de sus acciones y que, en algunos casos, resultan más determinantes que su propia formación inicial. De ahí la necesidad de develar esas concepciones para producir una transformación más profunda de sus prácticas pedagógicas.

Los relatos de los episodios críticos son escritos y completados en el transcurso del taller a medida que el grupo avanza en la implementación del método de investigación. Una vez escogidos los episodios, con ayuda del grupo, los protagonistas los reconstruyen externa e internamente. La reconstrucción externa la hacen con la intención de objetivar y rescatar el contexto en que el episodio sucede, recordando la textualidad de los diálogos ocurridos durante el mismo. La reconstrucción interna se hace para rescatar la subjetividad del protagonista: la emocionalidad con que lo vivió; la representación que se hizo de la situación vivida en el momento; y la racionalidad pedagógica que determinó su actuar. 
La siguiente etapa de la IP es la interpretación, en la que van develando las concepciones psico-socio-pedagógicas e institucionales subyacentes en los episodios descritos, con apoyo de la teoría, de modo de ubicar al docente en una red de interacciones que evidencia ciertas formas de establecer relaciones vinculares consigo mismo, con la institución escolar, con los demás docentes, y con los modos de aprender que favorecen en sus estudiantes.

Finalmente, los docentes recrean su mirada proponiendo racionalidades y acciones alternativas.

Los conceptos de grupo cooperativo y aprendizaje autónomo se explicitarán más adelante al evaluar los otros objetivos de la experiencia.

Esta sistematización se presenta en forma de un relato comprensivo del proceso llevado a cabo por los participantes, y se basa en las textualidades y en el análisis de los registros de las sesiones del taller.

El relato comprende tres apartados que corresponden a los tres objetivos planteados:

- Sobre la modificación del rol docente.

- Sobre la experiencia de participar en un grupo cooperativo.

- Sobre la concepción de aprendizaje.

Sobre la modificación del rol docente

Los principales temas abordados en las investigaciones protagónicas fueron:

- Relaciones docente-estudiantes: formas en que los profesores enfrentan problemas de disciplina en el aula o conflictos por agresiones sufridas por los estudiantes de parte de sus padres.

- Relaciones docente-apoderados: formas en que los docentes reaccionan ante conflictos con los apoderados.

- Relaciones docente-dirección (directores o jefes de unidades técnico pedagógicas): formas en que los docentes enfrentan conflictos con la autoridad, ya sea por cuestionar el proceder de los directivos para enfrentar agresiones de los apoderados, transgresiones de normas por parte de los estudiantes o decisiones que afectan al equipo de profesores. 
- Relaciones docente-docente: conflictos sobre la designación de tareas, la organización de los espacios comunes, divergencias sobre la evaluación docente o sobre las formas para enfrentar la relación con los estudiantes.

Los temas de conflicto con la dirección del establecimiento y con los pares fueron a los que más dedicaron su atención.

\section{Dificultades y aprendizajes para enfrentar la modificación del rol docente}

En las primeras reuniones surge el tema de la rivalidad entre antiguos y nuevos docentes. Lo expresan así: "dicen que nosotros llegamos a quitarles el puesto"; "los profesores de más edad te miran feo y hablan por detrás"; "por ser más jóvenes nos pasan los cursos más desordenados"; "cuando llegué a la sala de profesores, tuve que ganarme mi lugar"; "las sillas tienen nombres y te van corriendo"; "el clima de trabajo no es bueno"; "no confio en mis colegas"; "me dijeron: 'llegaste a la escuela del rigor'; "me tiraron a la pelea"; "no encuentro a nadie que me dé confianza"; "se siente una presión por el Simce, por ser profesor jefe, por quienes revisan las planificaciones"; "aqui todo se tapa y nadie dice nada"; "yo trato de resolver el problema por mi cuenta"; "yo estoy buscando un aliado"; "tengo miedo a ser despedida".

$\mathrm{Al}$ tratar de buscar las representaciones que están en juego en estos relatos, un participante distingue entre las intervenciones más institucionales y las más emocionales. Las institucionales atribuyen la mayoría de estos problemas a fallas de comunicación al interior de la escuela ("el director del establecimiento quiere canalizar algo y no sé por qué razón los conductos regulares se quiebran"); y las emocionales la atribuyen a problemas de rivalidad por el poder ("nadie puede llegar y ponernos el pie encima").

Esta distinción hace referencia a dos tipos de obstáculos que los profesores nóveles enfrentan para comprender el significado y sentido de su rol profesional. Unos obstáculos de carácter "epistemológicos", en cuanto a que son impedimentos cognitivos para procesar estas distinciones y operar

3 Todas las textualidades del presente artículo fueron extraídas de los registros de las sesiones. Estos son escritos inéditos. 
sobre la realidad (no saber por qué las cosas suceden de determinada manera, no tener elementos teóricos para explicarse las conductas de los profesores, etc.); y otros de carácter "epistemofílicos", en cuanto a que son impedimentos de orden emocional que obstaculizan la comprensión y el significado de estas relaciones (la rabia o la ira impiden objetivar y comprender por qué suceden las cosas como ocurren).

Frente a las desautorizaciones, agresiones y trato despectivo por parte de los docentes viejos, los nóveles se preguntan cómo construir su identidad profesional y ganarse el respeto de los mayores: ¿En forma individual o colectiva? ¿En qué momentos ellos se sienten responsables del conjunto de docentes y en qué momento sienten el deber de separar aguas y velar por su propia identidad profesional, aun a costa de pelearse con sus colegas de más edad? ¿Cómo construyen su rol docente, en colaboración o en ruptura con ellos?

Los grupos responden de distinta manera estas interrogantes. A ratos prevalece el sentimiento de ser invencibles: "tú tienes que ser más fuerte..."; a ratos el de sentir la necesidad de apoyo: "me sentí apoyada por UTP y no quise hacer nada más, sentí que ellos ya lo habian arreglado... "; y a ratos la necesidad de romper con lo establecido: "después que habia hablado con el inspector segui quedándome, quedándome... Pensé que no tenía que hacer más que eso... Pero después me di cuenta que sí, que tenía que hacer algo más...".

Estas alternativas reflejan una concepción distinta de liderazgo institucional y de la relación que se pudiera establecer entre autoridad y docentes nóveles:

- El director asume una actitud diligente para resolver y tomar decisiones en caso que ocurrieran situaciones conflictivas; que fuera un líder que se posicionara frente a la comunidad, usando su poder para resguardar la seguridad de sus estudiantes y profesores; y que estuviera al tanto de lo que sucede en su establecimiento. En el vínculo "director-docente" se esperaría que un director con tales características orientara al nóvel en su labor, acudiendo a su experiencia. En ese caso, el docente podría construirse a sí mismo como un profesional que escucha y que desea escuchar, 
que manifiesta interés en construir redes de apoyo, que requiere del otro, por tanto, como un profesional que sabe pedir ayuda.

- Pero si el director es autoritario, el docente podría asumir pasivamente su participación en el establecimiento, esperando respuestas y soluciones de los directivos, en vez de hacer propuestas para enfrentar las situaciones conflictivas.

Los participantes se dan cuenta que cuando un profesor espera que el director le solucione los problemas se está asumiendo un rol docente pasivo, que espera respuestas y soluciones; un rol docente que se asemeja mucho más al de un técnico que al de un profesional; un rol docente tributario del poder, más que complementario de la autoridad.

El análisis de un episodio es indicativo de cómo van develando su concepción de autoridad y la manera de entender el rol que deben asumir. Ante una reacción sorpresiva y enrabiada de un alumno, la profesora dice:

En ese momento me sentí vulnerable, sentí que se me escapaba la situación y que no sabia qué decir. Me sentí frágil, yo era la docente y se supone que tenía que tener una respuesta, tenía que saber actuar en ese momento... Pensaba 'tengo que decir algo, tengo que responder, no me puedo quedar callada... Pero cuando supe que no estaba preparada para decir nada, mi acción final fue guardar silencio.

Ante este episodio, el grupo reflexiona que la escuela le asigna al docente un rol de sabelotodo como un ser omnisciente, con absoluto dominio tanto de los temas de su asignatura como de los modos para enfrentar conflictos en el aula. Cuando el grupo logra develar esta concepción comienzan a cuestionar y resignificar sus supuestos: “¿Por qué tenemos tan metida la idea de creer de que si yo no digo nada soy lo peor, o que si yo respondo soy el bacán, soy el mejor?”.

Asumir que no saben los vulnera, los fragiliza y los inmoviliza. Sin embargo, es legítimo no saber, ya sea con relación a los contenidos de los programas o al cómo relacionarse con los demás en determinadas circunstancias. Aún más, explicitar abiertamente "no saber" es algo que los estudiantes agradecen y valoran, según la percepción de los docentes nóveles. 
Desde su crítica comienzan a construir una racionalidad alternativa diferente a la de la autoridad omnipotente: "Hay que aceptar los errores y sacarse la idea que uno tiene que saber todo. El proceso de aprendizaje también vale para uno". "Ahora trato de ser más relajada, porque creo que el hecho de estar obsesionada, asi como que tengo que actuar bien porque soy la profesora, no me sirvió de nada en ese momento". Y la reflexión termina imaginando una acción alternativa: "Podría haber dicho algo como la embarré, de verdad disculpa, no queria hacerte sentir mal'”.

Frente a episodios como estos, cuestionan su formación inicial, pues perciben que no han aprendido el manejo de situaciones de conflicto, evidenciando así una evaluación de sí mismos desde el "déficit" y no desde la "necesidad de aprender".

Cuesta distinguir al docente arrogante que se refugia en el poder que le da el conocimiento de su materia y que no permite que sus alumnos lo cuestionen, de aquel que es legitimado como autoridad sobre la base de sus competencias éticas: sinceridad, transparencia y coherencia. Sobre el vínculo que los docentes establecen con la autoridad (sea esta de los directivos o propia) para distinguir entre el profesional que es sumiso, del que es agresivo y del asertivo, se vuelven indispensables las preguntas: ¿Qué distingue a un profesor autoritario de uno que tiene autoridad?; ¿qué distingue a un director con liderazgo de uno autoritario?; ¿qué distingue a un equipo de docentes de un grupo de docentes?

En el taller se levantan hipótesis sobre la concepción de institución escolar. La escuela es una institución jerárquica en la que quienes están "más arriba" ejercen su poder en forma arbitraria (presiones, negaciones, agresiones) sobre quienes tienen menos poder, en este caso, los nóveles. La relación entre pares es asimétrica y no se buscan instancias de relaciones más simétricas, porque los viejos podrían perder su poder. La autoridad interactúa con quienes tienen menos poder desde una lógica que genera vínculos de dependencia, que niega los espacios de decisión de los nóveles y que los tiende a controlar y hasta invisibilizar.

También los participantes conjeturan sobre las emociones que están detrás de la manera de relacionarse con una autoridad que 
resalta las relaciones de poder asimétrico. Por ejemplo, en la escuela se construye e instala una relación con la autoridad fundada en la emoción del miedo: no se sabe cómo reaccionará la autoridad, no se sabe cómo manejar la situación, se teme recibir represalias, ser evaluado mal o perder el trabajo. Estas dificultades son de carácter "epistemofílico", por cuanto los impedimentos para conceptualizar un adecuado rol docente o una necesaria resignificación del rol, provienen del campo de lo emocional.

¿Cómo se relaciona el profesor nóvel con una autoridad que ejerce el poder de esa forma? El miedo tiende a inmovilizarlos y a impedir que se generen espacios de diálogo y relaciones más simétricas con la autoridad. Fruto del miedo, la relación que establecen con la autoridad es la dilación, continuar como si nada hubiese pasado, esperar otro momento para hablar, o definitivamente no hacer nada.

¿Se trata de una relación de sumisión a la autoridad?; ¿por qué no pensar que puede existir con ella la posibilidad de una relación asertiva y democrática?; ¿con qué concepción de autoridad, de liderazgo y de convivencia escolar están operando los profesores principiantes?; ‘ cómo se concibe el trabajo en equipo en los establecimientos? ¡existe una repartición equitativa de la carga laboral en los equipos de docentes? ¿por qué a los docentes nóveles se les somete a mayor presión de trabajo? ¿cómo enfrentar situaciones de conflicto con apoderados y estudiantes?

Estas y otras preguntas son las que debaten los docentes a partir de las investigaciones protagónicas y que les permiten cuestionar la manera en que ellos van asumiendo un rol docente de carácter profesional. El solo hecho de levantar estas preguntas abre la posibilidad de imaginar un rol docente alternativo.

Sobre el aprendizaje grupal

En los centros escolares, los docentes suelen estructurar pautas de conducta más competitivas que de cooperación, se resisten a confrontar experiencias y temen ser evaluados por sus pares. Las responsabilidades tienden a jerarquizarse y asumirse en forma individual. Las formas 
burocráticas de organizar el trabajo en las escuelas atentan contra el carácter colectivo del acto de enseñar. Resignificar el modo aislado en que trabajan los profesores hacia formas más cooperativas fue el segundo objetivo de aprendizaje de esta experiencia (Santoyo, 1981; Bleger, 1984) . $^{4}$

Abordar la tarea de investigación no es fácil, porque no todos los participantes tienen la misma disposición para conectarse con su subjetividad y, sobre todo, exponerse frente los demás. Este componente subjetivo es el que provoca una sensación de vulnerabilidad y temor. Los temores surgen del miedo a perder lo viejo, lo conocido, lo que de algún modo les da seguridad; y también del miedo a enfrentar lo desconocido y a sentirse vulnerable frente a lo que no entienden bien o todavía no controlan.

Sin embargo, la experiencia de trabajo en grupos operativos muestra que ellos van avanzando hacia formas más democráticas de trabajo en la medida que los participantes enfrentan sus temores. Esto se verá a propósito del análisis sobre los vectores del aprendizaje grupal, que son categorías que se utilizan para evaluar la progresión en la conformación de los grupos operativos (Bauleo, 1969).

\section{Afiliación o pertenencia}

Este vector observa cómo se da la relación entre individuo y grupo, si se sienten integrados al grupo y qué tan sólido es el sentimiento de comunidad que los participantes logran conformar.

Al percibir cambios en el modo de verse ellos mismos y de ver a los demás, identifican como aprendizaje el salto del trabajo individual al grupal: "estamos viendo a los que faltan, aprendimos a verlos... Ella estaba súper afligida en un momento y nadie le preguntó nada... Desde ese momento hasta ahora, si a alguien le ha pasado algo, nosotros le preguntamos ‘cómo estai?'”.

Para constituirse como un grupo cooperativo es necesario ponerse al grupo, lo que implica visibilizar a los otros y asumirse como un miembro

4 Los vectores son afiliación o pertenencia, cooperación, aprendizaje, comunicación, pertinencia y telé. 
más: "me he sentido parte de este grupo, tanto de las soluciones como de los problemas... El tema de la pertenencia ha sido súper significativo para mi...".

También se percibe pertenencia en la manera cómo el grupo acoge las necesidades y dificultades de los demás: "hay días que llego cansado ya que en el colegio hablo todo el día... y en el grupo me siento cómodo, otros hablan... Tal vez no llegamos siempre a la tarea, pero como grupo nos supimos cohesionar...".

Los docentes nóveles dicen haber construido en los talleres un "grupo continente", acogedor, en el que sus miembros se visibilizan, se sienten pertenecientes y disfrutan de la compañía de los demás.

\section{Cooperación}

Este vector atiende la relación entre los integrantes para colaborar en la solución de la tarea, y cuánto interés ponen en ayudarse unos a otros (Orgaz \& Ferreira, 2009). El grupo existe en función de la tarea de investigación. Esta les exige poner en práctica habilidades conjuntas para desentrañar las racionalidades psico-socio pedagógicas e institucionales que subyacen en los episodios analizados; les exige un "pensar social".

Para enfrentar este desafío ellos cuentan con el grupo, que se transforma en un "grupo-continente", apelando al vínculo de confianza que han construido:

Llegaba y me gusta mucho esto del grupo; pero cuando nos daban la tarea no entendía lo que habia que hacer... después cuando comenzábamos todos a hablar, entonces me daba cuenta de lo que se trataba... Al comienzo no sabiamos pa' dónde iba la micro, pero nos cooperábamos y llegábamos a una solución.

Según la evaluación de los participantes, la cooperación no solo consistió en tener una disposición adecuada para la reflexión y el agrado de estar con los demás, sino también implicó cumplir con responsabilidades que el propio grupo se asignaba. Así, la cooperación es fruto del autoanálisis y autocrítica sobre los modos de participación: "Uno tiene ganas o ansias de contar lo que le está pasando... pero después de cada taller uno se queda pensando si la forma en que actuó fue o no la adecuada". 
En la cooperación surge el tema del liderazgo: ¿¿Hasta qué punto un grupo cooperativo requiere de ciertos liderazgos que conduzcan al grupo hacia la tarea? Una integrante declara: "El grupo ha facilitado la tarea, porque alguien ha actuado como la 'vocera' para que la finalicemos... Al principio nos costó bastante llegar a la evaluación final... pero el grupo ha facilitado el abordaje de la tarea”. Al usar el concepto de "vocería” se infiere que los roles de liderazgo fluyen de acuerdo a los distintos momentos que el grupo está viviendo, de modo que no necesitan rotular a alguien como "líder" permanente del grupo.

Pero el liderazgo es también un tema que los tensiona: "Siempre me caracterizo por ser un líder, trato de que los otros hablen... Ahora estoy como que quiero hablar o que hablen otros que no siempre hablan". Otro declara: "bubo una vez que yo hablé mucho... y pensé voy a dejar que el resto hable”. En otro momento una persona afirma que optó por el silencio como un acto de "autocensura" y para probar al grupo: "Lo hice no por sabotear; quería ver quép pasa si esta locutora cierra la boca; me reprimi y me di cuenta que se trabaja igual...".

En este grupo el silencio fue "significado" por algunos como obstáculo para la cooperación. Solo una persona se declara contraria a esta idea: "El silencio también es una virtud... doy mi opinión cuando siento que tengo que aportar algo diferente; si se trata de lo mismo que el resto dice, prefiero disfrutar el silencio".

\section{Aprendizaje}

Este vector se refiere a la internalización de un nuevo modelo de relación y muestra la aptitud del grupo de aplicar el conocimiento adquirido a nuevas situaciones. Integra la posibilidad de observación, de conceptualización y de poner en práctica la teoría presentada. Tiene que ver también con la unidad del pensar con el sentir, ya que el aprendizaje no es únicamente intelectual sino que incluye el registro de lo afectivo.

Situado en el espiral -en el cono invertido que avanza pasando por el mismo lugar pero en un estadio de desarrollo diferente-, el aprendizaje se visualiza como el remezón necesario para volver a ajustarse, como el 
proceso de modificar las relaciones vinculares con el medio y consigo mismo. Estos fueron aspectos de mucha resonancia: "En un momento le dije y le planteamos a X que hablaba demasiado..."; "Finalmente $Z$ terminó contando su relato, a pesar de que se declaraba como espectador...".

Ante la pregunta "¿en qué se han modificado en el desarrollo de este taller?" dicen:

Sé que soy pasajero de esta micro, traté de cambiar... de no tenerle miedo a la dirección... tuve que empezar a superar mis temores; (el taller) me dio más seguridad... ahora el grupo-curso lo manejo diferente, que es lo que yo puedo manejar dentro del colegio.

De repente hablo mucho, hablo demasiado... Aun asi dentro del grupo senti que en mi hubo una modificación... traté de bajar los niveles de ansiedad... eso también me ha servido en mi ambiente: es mucho mejor escuchar qué es lo que está pasando, escuchar muy bien lo que están diciendo los demás, escuchar qué es lo que se intenta decir $y$ después opinar...

Superar el egocentrismo; interesarme por lo que dice el otro; no decir 'yo tengo un problema, o esto me pasa a mí no más'; también interesarme por preguntarle al otro... preocuparse del resto pasa por superar nuestro ego como profesores que solo queremos hablar...

El obstáculo que yo tenía era el miedo de decir algo incoherente y que ustedes no me entendieran... Pero aqui me senti importante, ustedes me hicieron sentir eso, me hicieron sentir importante y que lo que decía si tenía valor...

Mirar de frente los propios temores es el paso necesario para activar los aprendizajes; de esta forma la timidez, la inseguridad y el ego son interpretados como "vallas" (obstáculos), pero al hacerlas visibles se transformaron en posible "trampolín" hacia el aprendizaje, tanto para los protagonistas como para el grupo. 
Considerando el conjunto de los vectores desde la perspectiva de los aprendizajes, la necesidad del otro aparece como uno de los pilares más sólidos en el proceso grupal. En un momento de mucha intensidad los docentes perciben que si aprender es cambiar, irremediablemente requieren de los otros, de un vínculo de confianza, de cooperación y afiliación:

Empecé a tener la necesidad de escuchar a $X$, a la $Y \ldots$ Un tema es callarse, pero otro tema es querer escucharte a ti, saber cuál es tu opinión... Escuchar al otro es pedirle que me dé su punto de vista...

\section{Comunicación}

Este vector se relaciona con los mensajes, canales, códigos con que los miembros del grupo se comunican; cómo se da la comunicación, qué sucede con el "ruido" y cómo se manejan los "malos entendidos".

Se señaló como aprendizaje significativo la necesidad de escuchar a los demás desprendiéndose de sí mismos para transitar al "nosotros" identidad colectiva-:

No es malo saber escuchar, dejarla que se exprese... no irme a mi situación, sino meterme en la situación que tú estás viviendo. Eso trataba de hacer, 'qué te pasó, qué hiciste'... cuando empiezas a pensar en lo que te ha pasado a ti, dejas de escuchar.

Aquí se explicitan dos formas de escuchar: una instrumental y autocomplaciente, y otra al servicio de los demás y de sus necesidades.

Sin embargo, la ansiedad por no soportar el silencio a veces no permite escucharse y escuchar los mensajes del cuerpo: "Este es mi carácter... cuando uno habla mucho también es un problema... nadie va a opinar; eso es lo que pasa en este grupo... lo que falta es seguridad personal a la hora de opinar". Otro declara: "estoy ahogada; hablo, hablo y después me quedo callada". Quizás lo que ambos demuestran es falta de confianza en la capacidad del grupo para comunicarse y resolver sus problemas, o tal vez poca paciencia para permitir que los silencios dialoguen en la conversación.

¿Cómo potenciar la participación equilibrada en los talleres? ¿Cómo apelar al silencio sin ser sumiso y al monólogo sin ser agresivo? 
En un grupo cooperativo los espacios de comunicación asertiva son fundamentales. Con este matiz se cultiva el diálogo, germina una nueva forma de vínculo y la posibilidad de construir colectivamente muchos saberes:

Yo lo he pasado muy bien en el grupo; ha sido muy agradable y significativo este momento... En cuanto a los espacios de comunicación que se han dado aqui, estoy muy satisfecho por haber podido generar diálogos con mis compañeros de trabajo, sin necesidad de un mediador. El grupo se va articulando por la mutua representación interna que cada quien tiene de los demás y fluye a través de una grata comunicación interpersonal.

Uno de los grupos evaluó positivamente las intervenciones que provocaban risas, pese a las interrupciones que causaban: "La verdad es que interrumpia"; otra persona responde: "eso se dio súper bien; reirnos fue una buena terapia"; "es parte de la comunicación", señala el primero: y otro agrega: "... servía para tomarse con humor las cosas... me sirvió mucho".

Los malos entendidos y los mensajes distorsionados fueron el contrapunto del buen humor. Desde ellos se van dibujando nuevas conversaciones y vínculos. Una participante que se siente agredida por la coordinación cuando esta no le da la palabra por estar excedido el tiempo del trabajo grupal, se expresa así:

Cuando llegué al taller venía con otra percepción y me acuerdo del conflicto que tuve con el profesor; ahi me fui mal, me fui hacia dentro y mi perspectiva fue apoyar cuando fuera necesario, y subrayado necesario... asi lo hice porque me molestó y no me gustó lo que usted hizo conmigo; y senti el apoyo del grupo; por eso creo que los lazos son más fuertes con ellos que con ustedes... Eso me descolocó...

La tensión vivida entre esta integrante del taller y la coordinación fue retratada en la siguiente conversación: "De hecho yo pensé que no ibas a venir más", le dice una persona a la involucrada. Alguien agrega: "yo pensé exactamente lo mismo... Pero en todo caso encuentro súper válido eso de respetar los tiempos... nadie respeta los tiempos; asi que igual es válido"; "pero a lo mejor fue muy brusco, porque era la primera vez, fue súper chocante la situación para todos, me dio lata", replica una docente; y otro agrega: "a 
mi también, fue una situación que nos descolocó a todos; todos quedamos pa' adentro... todos nos mirábamos... fue atroz".

Sin duda que el grupo pasó por una situación de incomodidad y desajuste. En sesiones posteriores buscaron medios para reacomodarse y recomponer los vínculos con la coordinación, tratando que este episodio no dañara la comunicación con ella. La coordinación, por situarse en una posición de descentramiento con relación al trabajo grupal, es susceptible de recibir todo tipo de transferencias, principalmente aquellas que se relacionan con conflictos con la autoridad. Sin embargo, este episodio no permitió develar y analizar qué conflictos se pusieron en juego, toda vez que ni el participante ni los miembros del grupo lo abordaron.

Finalmente se destaca una concepción diferente del rol docente, con capacidad y herramientas para modificar su realidad escolar: "Es una experiencia importante que se podría replicar con nuestros otros colegas, poder crear espacio de reflexión, donde generemos nuevos conocimientos y soluciones sobre nuestros problemas en las prácticas educativas". El aprendizaje que se describe gatilló un cambio en la forma de entenderse a sí mismo y de comprender la relación con sus compañeros de trabajo. "El obstáculo es ese: creer que es el medio el que te imposibilita hacer algo, siendo que es uno el que tiene que tomar las decisiones".

\section{Pertinencia}

Este vector mira la relación entre grupo y tarea, mostrando el tiempo, la forma y el deseo de resolverla; qué tan pertinente es el grupo en el análisis y la resolución de los temas que lo convoca.

Algunas de las dificultades enfrentadas se debieron al desconocimiento de la metodología de trabajo:

Yo siento que al principio me costó mucho enchufarme en lo que teniamos que hacer, sobre todo en la primera reunión, no entendia qué habia que hacer, porque nunca habiamos trabajado en un grupo asi... era muy extraño el sistema de trabajo...

Otro dice:

Me gusta mucho la modalidad de trabajo... en la Universidad 
habia un profesor que proponia este tipo de trabajo, un trabajo más autónomo, no tan frontal, de diálogo, proponía la tarea y cómo lo teníamos que hacer... finalmente el profesor colapsó con el sistema... esta experiencia de sentarnos, mirarnos, regularnos (no funcionó).

La falta de responsabilidad para asumir lo que el grupo se había asignado es interpretada como déficit de pertinencia:

Ahora la pertinencia creo que ha sido el tema que más me ha costado desarrollar. Un mal hábito mio de no hacer la tareas... muchas veces se dificultó el trabajo de nosotros, porque muchos llegaban con su tarea, pero yo no llegaba con la mía... eso dificultaba el trabajo, nos teniamos que poner de acuerdo y yo por lo menos tenía que rebobinar en lo que estaba.

En algunos momentos se cuestiona la forma en que el grupo enfrenta la tarea: "No hubo tanta coherencia, ni congruencia... Me pasó que se hablaba de un tema, salía otro, nos ibamos y dejábamos de lado el objetivo que se quería lograr... En algunas instancias no habia congruencia con lo que se estaba trabajando". Luego: "nos íbamos por las ramas y nos olvidábamos del problema del compañero... en el momento de la tarea nos disgregábamos".

Darse cuenta de la disgregación o de "irse por las ramas" es ya un paso hacia la búsqueda de pertinencia.

Telé

Este vector se refiere a la relación afectiva entre las personas; permite visualizar el impacto que una persona puede tener en los otros. La Telé puede ser positiva o negativa según el deseo o el rechazo que surge entre integrantes de un grupo para trabajar o no con el otro.

Creo que fue lo más logrado. El grupo es bueno. Hay mucha telé.. Es que se generaron lazos... Nos sirvió para liberar tensiones y tomarnos con humor las cosas que nos pasan... A mi me sirvió mucho el grupo... Nos acercamos. Nos vemos con cariño a pesar de que nos veamos una vez al mes... Empecé a tener la necesidad de escuchar. 
Estas palabras expresan el valor afectivo que adquiere el grupo para algunos de los participantes en el proceso de aprendizaje. Se robustece la identidad personal y también las identidades colectivas en los imaginarios que recrean prácticas sobre el "ser docente".

En los talleres se constata la ausencia de estos espacios de afiliación, cooperación, aprendizaje y comunicación en los establecimientos donde los nóveles trabajan: "Esta es la única instancia que hemos tenido de hablar de nosotros, porque al parecer en la escuela nadie nos pesca... Es rico saber que no eres el unico... y tener este momento de decir 'esto me pasa".

El principal obstáculo que tiene que enfrentar un grupo es conocerse; creo que nosotros lo hicimos súper bien... Para el tiempo que tuvimos, aprendimos a conocer algo personal de los otros, además de lo que exponíamos acá... Si no me permito conocer al otro, no me permito conocerme yo mismo.

Sobre la concepción de aprendizaje

Resignificar un modo de aprender dependiente de uno, de carácter autónomo fue el tercer objetivo de aprendizaje del taller (Hevia, 1988).

El modo de aprender autónomo que favorecen los TED procura convertirse en una experiencia pedagógica que convenza a los profesores de la necesidad de romper los lazos de subordinación y dependencia en las maneras que los estudiantes tienen de relacionarse con sus aprendizajes, y que muchas veces ellos como docentes estimulan. Los talleres pretenden crear condiciones que favorezcan en los nóveles modos de aprender autónomos que después puedan recrear con sus estudiantes.

Los TED consideran que todo aprendizaje es una modificación más o menos estable de pautas de conducta, o de las maneras que las personas tienen de estructurar las relaciones que establecen con el mundo, con los demás y consigo mismo. Estas modificaciones no se pueden hacer sin enfrentar las resistencias que brotan tanto desde la horizontalidad como desde la verticalidad del sujeto. 
Todo aprendizaje supone la capacidad de poner en duda la manera como uno ha ido articulando las formas de comprender y de actuar en la realidad. El aprendizaje aparece como un enfrentamiento entre lo viejo (pautas de conductas estereotipadas) y lo nuevo (conductas que se están gestando en el mundo interno y que no han llegado a cristalizarse en nuevas pautas de conducta), lo que provoca miedo y engendra todo tipo de resistencias.

El aprendizaje supone una disponibilidad del sujeto para cambiar, pero también condiciones objetivas que le faciliten esa tarea y le permitan vencer esos temores. El aprendizaje es una comprensión integradora, espiralada, modificante y crítica de la experiencia vivida. El punto de partida de este proceso es siempre el reconocimiento de los quiebres o conflictos. Solo se aprende enfrentando el conflicto, no negándolo.

Los aprendizajes son esencialmente personales, pero un grupo puede actuar como movilizador de los comportamientos de sus integrantes. En los TED, el análisis de un episodio moviliza la verticalidad de cada uno de los integrantes del taller: por momentos el grupo puede ser atractivo, porque uno se siente acogido; pero en otros, el grupo puede amenazar y desarticular.

Hay una diferencia entre la conducta "molar" y la "molecular". Una conducta "molar" se explica por la motivación con que actúa el sujeto (el por qué: factores internos y externos que influyen; campo ambiental y psicológico en que se da); por la finalidad o significado con que actúa (el para qué); y por la estructura de la conducta o la manera de establecer el vínculo entre el sujeto y el objeto de la conducta (toda acción es una relación entre un sujeto y un objeto) (Zarzar, 1980).

El aprendizaje consiste en modificar la manera de estructurar o modificar una pauta de conducta. Llevar a cabo esta modificación es más difícil que cambiar una "conducta molecular", porque se trata de modificar el mundo interno del sujeto, y con ello la posibilidad de vincularse de otra manera con la realidad. Por tanto, solo es posible observar signos de aprendizaje, que son como la punta del iceberg que deja por debajo de la 
línea de flotación las ocho novenas partes del témpano. Estos signos son solo indicios de algunas modificaciones que le pueden estar ocurriendo al sujeto en su mundo interno y que no son visibles a simple vista para las otras personas.

Pero así como hay signos de aprendizaje, también hay signos de no aprendizaje. Esto ocurre cuando las personas se aferran a maneras estereotipadas de estructurar conductas, ya sea porque les da miedo enfrentar los quiebres, no se arriesgan a experimentar una nueva manera de actuar, o no tienen la visión y capacidad de enfrentar sus propias resistencias al aprendizaje.

\section{Signos de aprendizaje}

- $\mathrm{Al}$ comienzo de las sesiones se advierte una dependencia de los participantes con respecto a la coordinación. Se espera que sea ella la que dirija la reunión, que dé la palabra, que haga las preguntas. Hay un desconcierto inicial respecto al rol descentrado que asume la coordinación. Un participante dirigiéndose al coordinador pregunta: “¿Tenemos que abordar temas pedagógicos, administrativos, o temas curriculares?.. Necesitamos un marco".

Otro expresa: "Necesitamos un marco, un coordinador que nos dirija, que nos dé la palabra... ". Sin embargo el marco y la tarea estaban dadas en el momento informativo y se les solicitaba que decidieran cómo abordarla. Con el tiempo, esa dependencia se disipa y los grupos avanzan hacia formas más autónomas de gestión: "Somos nosotros los que tenemos que ponernos de acuerdo en cómo abordar la tarea"; "¿Por dónde empezamos? Pensemos que somos dueños de nuestro tiempo"; "Lo otro que podemos hacer es regularnos nosotros mismos...".

- Después de algunas sesiones ellos dicen tener mayor claridad sobre cómo evaluar el aprendizaje del trabajo grupal, y que en el momento de evaluación aprendieron a tomar distancia de lo 
que estuvieron realizando. La toma de distancia del sujeto que conoce con el objeto de conocimiento es un elemento clave para ir elaborando y reforzando un modo de aprender autónomo.

- Reconocen que algunos factores les ayudaron a sus aprendizajes: escribir sus episodios ayudó a revivir situaciones, a conectarse con sus experiencias y a concentrarse en su subjetividad; leerse unos a otros ayudó a conocerse en una dimensión más profunda; mayor claridad de la consigna (explicación de la tarea grupal) ayudó a no divagar al inicio del momento grupal; y la retroalimentación o devolución que la coordinación hacía sobre las sesiones anteriores en el momento informativo, ayudó a desentrañar las racionalidades en juego en sus episodios y a descubrir maneras de relacionarse en su trabajo grupal.

- Aprendieron que el grupo no solo escucha y contiene, sino que también se puede concebir como un espacio para problematizar: "Después de la pregunta (sobre la significatividad de los episodios) aprendi que los episodios hay que contextualizarlos y que hay muchas cosas que no aparecen en el papel...", refiriéndose a los episodios que habían escrito y expuesto.

- Una participante evaluó así su proceso:

Yo puse (en el episodio escrito) que actué bien, pero con todo lo que aprendi hoy día tengo que cambiar mi relato... porque estuve dos años de mi trabajo sin decirle nada a nadie... me quedé callada muchas veces, me decian cosas horribles... pero me he dado cuenta que aqui he cambiado harto... ahora estoy totalmente distinta; pienso que si hay disposición de mi parte para cambiar, por mi misma, para poder sentirme bien, sentir seguridad en lo que estoy haciendo... por eso voy a cambiar...

Cómo hacer frente a las dificultades de aprendizaje

Una de las dificultades señaladas fue experimentar ansiedad frente al grupo por los silencios largos, por los temas abordados que a veces 
provocaban remezones emocionales, sobre el uso del tiempo con un afán eficientista. También ansiedad frente a quienes no participaban, a quienes creían saberlo todo, o a quienes decían que todo era más de lo mismo. Ansiedad por no comprender el rol descentrado de la coordinación, o por cierta dispersión en la tarea. La ansiedad también la expresan como intimidación, molestia y aprensión.

Es cierto que con mucha ansiedad no se aprende, pero sin ansiedad, tampoco. El punto es cómo mantenerla en un nivel equilibrado que permita que esta funcione como una señal de alarma, que no bloquee la energía grupal, pero que tampoco la consuma.

Hay dos conductas grupales extremas que evitar. Una es aquella en la que hay mucha ansiedad y poca distancia frente a los temas tratados, otra en la cual no hay ansiedad y el grupo no trabaja porque ya "lo sabe todo". En ambos casos la ansiedad opera como un enemigo del aprendizaje y se convierte en un estereotipo en la manera de estructurar la conducta de aprender.

Una equilibrada dosis de ansiedad es necesaria para mantener la capacidad de asombro ante lo desconocido y sostener preguntas abiertas que ayuden a buscar nuevas maneras de relacionarse. No hay investigación posible y la investigación es la tarea central de los TED sin cierta dosis de ansiedad.

En síntesis, la metodología de los TED aplicada en esta experiencia con docentes nóveles avala la importancia de utilizar instancias de aprendizaje basadas en la investigación y en la colaboración grupal para favorecer la inserción profesional desde una comprensión más profunda de cómo se gestionan los centros escolares.

Los TED demostraron contribuir en la formación de una mirada crítica sobre cómo asumir un rol docente alternativo a las concepciones tradicionalmente arraigadas en nuestra cultura escolar, como son las formas individualistas de trabajo, o el estilo de aprendizaje autoritario y dependiente. 


\section{Referencias}

Bauleo, A. (1969). El Grupo Operativo. Recuperado el lunes 06 de junio de 2011, del sitio Web Área 3, Asociación para el Estudio de Temas Grupales, Psicosociales e Institucionales: http://www.area3.org.es/htmlsite/ resultdet.asp?id=156\&type $=1$

Bauleo, A. (1970). El proceso de aprendizaje grupal. Recuperado el lunes 06 de junio de 2011, del sitio Web Psicología Grupal, Análisis Institucional de la Escuela Pichón-Riviére: http://www.psicologiagrupal.cl/ bauleo/clases/proceso_bauleo_cl.html

Bleger, J. (1984). Temas de psicología (entrevistas y grupos). Buenos Aires: Edición Nueva Visión.

Hevia, R. (1988). Cuaderno N4: Aprendizaje y evaluación en los TED. Santiago: PIIE.

Inostroza, G. (1996). Comp. Talleres Pedagógicos: Alternativas en formación docente para el cambio de la práctica de aula. Santiago: Dolmen Ediciones.

Orgaz, M. \& Ferreira, N. (2009). Una experiencia de intervención organizacional en el "vector comunicación". Recuperado el martes 07 de junio de 2001, del sitio Web Psicología Grupal, Análisis Institucional de la Escuela Pichón-Riviére: http://www.psicologiagrupal.cl/documentos/articulos/vectorcom.html

Peralta, L. (2009). Diagnóstico de la inserción profesional de profesores nóveles en escuelas municipalizadas. Estudio exploratorio en la V Región - Comuna de Valparaíso. Recuperado el viernes 07 de enero de 2001, del sitio Web Proyecto de Inserción de Docentes Nóveles en la Educación Municipalizada Chilena: http://docentesnoveles.cl/pages/home

Peralta, L., Martínez, M. \& González, P. (2011). La identidad docente en profesores nóveles: ¿apóstoles?, ¿técnicos? o ¿intelectuales transformativos? En I Congreso Internacional Educación, Cultura \& Sociedad. Universidad Academia de Humanismo Cristiano. Santiago, Chile.

Pichón-Riviére, E. (1972). Del psicoanálisis a la psicología social. Recuperado el 06 de mayo de 2011, del sitio Web http://www.elortiba.org/ pichon 1.html

Pichón-Riviére, E. (2008). El proceso creador. Del psicoanálisis a la psicología social III (17a Ed.) Buenos Aires: Edición Nueva Visión.

Pichón-Riviére, E. (2010). Teorías del vínculo (27a Ed.). Buenos Aires: Edición Nueva Visión.

Santoyo, R. (1981). Algunas reflexiones sobre la coordinación en los grupos de aprendizaje. Perfiles Educativos, 11, 3-19. 
Vera, R. (1988a). Cuadernillo N¹: Marco Global de los talleres de Educación Democrática. Santiago: PIIE.

Vera, R. (1988b). Cuaderno N²: Metodología de Investigación Docente: la Investigación Protagónica. Santiago: PIIE.

Vera, R. (1988c). Cuaderno N³: Rol del Coordinador en los TED. Santiago: PIIE.

Zarzar, C. (1980) La Dinámica de los Grupos de Aprendizaje desde un enfoque Operativo. Perfiles Educativos, 9, 14-36.

Zarzar, C. (1988). Grupos de aprendizaje. México: Nueva Imagen.

Fecha de recepción: 04 de agosto de 2011.

Fecha de aceptación: 06 de diciembre de 2011. 
